\title{
Herd Behavior in the Insurance Market: A Survey
}

\author{
Fan Liu $^{1}$ \\ ${ }^{1}$ John L. Grove College of Business, Shippensburg University, Pennsylvania, USA \\ Correspondence: Fan Liu, John L. Grove College of Business, Shippensburg University, Pennsylvania 17257, \\ USA. Tel: 717-477-1786. E-mail: fliu@ ship.edu
}

Received: July 30, 2015

Accepted: September 2, 2015

Online Published: October 25, 2015

doi:10.5539/ijef.v7n11p154

URL: http://dx.doi.org/10.5539/ijef.v7n11p154

\begin{abstract}
We conduct a survey to examine herd behavior in the insurance market. Following prior studies on consumers' use of information sources in their purchase decision-making processes we develop hypotheses that explore the relationship between selection of information sources and herd behavior among potential insurance buyers in the market. Our results strongly support contentions that insurance buyers are significantly influenced in their choices by recommendations from different information sources and they do use these as herd cues to infer insurance product quality when making their own purchase decisions. In particular, our findings suggest that potential insurance buyers are more likely to be influenced by collective intelligence than by insurance experts.
\end{abstract}

Keywords: herd behavior, information source, recommendation, decision-making process, insurance market

\section{Introduction}

One interesting human behavior is that people usually imitate each other when they are free to do as they please. This social phenomenon results in herd behavior. For example, books listed as New York Times bestsellers are easily sold well enough to continue as bestsellers. There has been much interest in the extent to how consumer purchase intentions or decisions in the market are characterized by herd behavior. Such an interest stems from the effects that herding may have both on market's stability and on the market's ability to achieve allocative and informational efficiency.

Consumers commonly use the evaluations of others from the market as an instrument or indicator to measure specific product quality while making their own purchase decisions (Park \& Lessig, 1977). In the field of insurance, consumers rely more on product recommendations or evaluations in their decision-making processes due the fact that it is relatively difficult for them to inspect or experience the "quality" of the insurance products prior to the purchase. (Note 1) This makes herding more prominent in the insurance market. For example, recommendations or evaluations from family relatives or close friends are more likely to be trusted and followed by consumers when they purchase insurance policies. Insurance products sold from leading insurance firms are purchased more frequently by consumers partly because they believe that the level of popularity implies high quality.

Prior studies in consumer research have discussed information sources and herd behavior in great depth (e.g., Andreasen, 1968; Ansari et al., 2000; Lascu \& Zinkhan, 1999). However, little or no empirical research has been conducted to test such herd behavior in the insurance market. Insurance firms are eager to understand such behavior since they may successfully induce consumer purchase intentions by creating novel and interesting consumption experiences. Furthermore, insurance regulatory agency may also take advantage of such herding to guide consumers make better decisions. In this paper we take one step toward addressing this gap in prior research and focus on exploring herd behavior among potential buyers of insurance in the market.

Our paper contributes to the existing literature on herd behavior in two aspects. First, despite the mechanisms for individuals to herd that prior research has theoretically identified from the capital market, there has been little or no work in addressing the herd behavior in the insurance market. (Note 2) Building on literature related to consumers' use of information sources in the decision-making process, we develop hypotheses that explore the relationship between selection of information sources and herd behavior among potential insurance buyers in the market. This study finds that potential buyers of insurance are strongly influenced in their choices by recommendations from different information sources and they do use these sources as herd cues to infer product quality when making their purchase decisions. Second, compared to other studies on herd behavior, our 
empirical results not only indicate the existence of herding among consumers in the insurance market but also disentangle impact of different information sources on herd behavior. More specifically, by conducting a well-designed survey, we are able to observe and measure how each information source affects consumers' decisions when conflict in information exists. This finding is critical because it improves our understanding how consumers process these information sources when they use them in the decision-making process.

The rest of this paper is organized as follows. Section 2 presents an overview of literature in related research areas. Section 3 proposes our hypotheses. Section 4 describes the design of the survey and section 5 illustrates the main results. Section 6 concludes and discusses the implications.

\section{Literature Review}

Asch (1956) describes herding as a social phenomenon in which individuals are strongly influenced by the decisions of others. Banerjee (1992), Bikhchandani et al. (1992), and Welch (1992) conduct theoretical research on herd behavior and find that agents with private information will disregard such information and herd after a finite number of choosing their own actions. This important result provides a rationale for the imitating behavior that we observe in consumers' decision-making processes.

Literature in empirical finance is surveyed in its relation to behavioral principles (Shiller, 2001). Avery and Zemsky (1998) examine herd behavior in the financial market and show that the presence of an efficient price mechanism makes an informational cascade impossible when the price is efficiently set by a market maker according to the order flow. In light of prior research, Cipriani and Guarino (2005) study herd behavior in a laboratory financial market. By observing subjects' trading strategies, they conclude that agents should never herd. However, in some cases, they find subjects ignore or decide not to take advantage of their private information to trade. Cipriani and Guarino (2009) further recruit financial market professionals to investigate herd behavior in a laboratory environment. By using a strategy-like method, they successfully detect herd behavior directly by observing subjects' decisions for all realizations of their private signals.

Consumers make decisions based on existing information. However, when facing plentiful information, they often imitate others rather than making decisions based on existing conditions (Bonabeau, 2004). Such imitative behavior can be derived from rational inferences based on the decision information of others that dominates individual signals (Anderson \& Holt, 1997) and lead to the formation of informational cascades (Bikhchandani et al., 1992). Research related to the use and influence of recommendations on consumers considers recommendation sources primarily as information sources and will influence consumers' decision-making processes (Senecal \& Nantel, 2004). This implies that when product evaluations of others, treated as cues for eliciting herd behavior, are used by consumers to indicate product quality, herd behavior occurs (Chen, 2008). If much is known about the different information sources that are possibly contemplated by consumers in the decision-making process, however, little is known about how such sources, especially in an insurance market, impact consumers' choices.

Literature focusing on consumers' decision-making processes in the insurance market either argues whether insurance product quality, price, and insured's switching cost may have impact on consumers' choices (e.g., Cummins et al., 1974; Dahlby \& West, 1986; Laury \& McInnes, 2003; Schlesinger \& Schulenburg, 1993) or emphasizes that distorted beliefs concerning the probability and size of potential losses, individual time preference and risk attitude may affect insurance decisions (e.g., Johnson et al., 1993; Kunreuther \& Pauly, 2004; 2005; Liu, 2014). However, there is no discussion in the literature that clarifies the influence of information sources as herd cues on potential insurance buyers' decision-making processes in the market. In this paper, we develop a set of hypotheses building upon a rich literature on herd behavior and a well-designed survey to address this issue.

\section{Hypotheses}

As noted above, this work postulates that information sources providing insurance product recommendations will influence the insurance buyers' decision-making processes and further elicit herd behavior in the market. We thus formulate the following list of general hypotheses.

\section{H1. Recommendations from insurance experts will be followed in a great proportion by insurance buyers.}

It is suggested by Kelman (1961) that credibility represents expertise and trustworthiness. McGuire (1969) argues that expertise can be considered as the perceived ability of an information source to know the right answer and trustworthiness as the perceived information source's motivation to communicate this expertise without bias. In addition, it has been shown in the literature that recommendations from experts are found to be positively correlated with consumers' attitudes toward their behavioral intentions. (Note 3) Thus, we believe that 
ratings of insurers from insurance experts, treated as cues for eliciting herd behavior, will positively influence consumers' choices.

\section{H2. Recommendations from other consumers will be followed in a great proportion by insurance buyers.}

Gilly et al. (1998) and Senecal and Nantel (2004) both suggest that evaluations from other consumers as information provide by impersonal source is believed to have much impact on consumers' decision-making processes. Consumers may not be familiar with each other, but are essentially alike and have relatively equal intention or desire to give and receive the best information. Wangenheim and Bayon (2004) argue that source of similarity indicates the degree of similarity between the source of a recommendation and potential customers. Because individual consumers implicitly assume that similar people have similar preferences, they consider aggregated evaluations or opinions from others are informative and diagnostic (Chen, 2008). Herein, we believe that ratings of insurers from other consumers will have positive influence on insurance buyers' choices.

\section{H3. Compared to recommendations from insurance experts, recommendations from other consumers are more likely to be followed by insurance buyers.}

We initially anticipate that the recommendations from other consumers will be perceived as less expertise. However, according to the discounting principle of attribution theory proposed by Kelley (1967), "other consumers" as recommendation source should be perceived as more trustworthy than "human experts" due to the fact that the experts are more susceptible to non-product related attributions. For instance, a certified financial planner who recommends an insurance product on insurer's website may be perceived as less trustworthy by consumers than if $\mathrm{s} / \mathrm{he}$ recommends the same insurance product but on an independent third party website. (Note 4) In other words, consumers tend to be influenced more by collective intelligence than by a small group of experts. (Note 5) Thus, we propose that ratings of insurers from other consumers will have more positive influence on buyers' decision-making processes than ratings from insurance experts in the market.

\section{Survey}

\subsection{Survey Description}

We recruited subjects from undergraduate programs at Shippensburg University. This was a paper and pencil survey and it involved a total of 97 students. The majority of subjects were between 20 and 22 years old (84\%). Sixty percent of the subjects were male, $77 \%$ were business major, $100 \%$ had driving license and $23 \%$ purchased their own auto insurance policy. Subjects had no previous experience with this survey and voluntarily signed up to participate to receive extra credit.

Survey consisted of two sections. Questionnaires in section 1 mainly collected demographic information from subjects. They were asked to identify their age, gender and major. Besides, information regarding subject's driving license and previous insurance purchase experience was also collected. By eliciting subjects' insurance purchase experience, we are able to examine whether recommendation sources have same level of impact on subjects who have insurance purchase experiences.

In section 2 of the survey, subjects were asked to shop for their auto insurance policy in the hypothetical market where only two insurers, insurer A and insurer B, were assumed to be available. Information about each insurer's sales revenue, ratings of the insurer from an insurance expert and from other consumers were available in each scenario to help subjects make their purchase decisions. (Note 6) In all, 8 scenarios were presented. Among these scenarios, variables used to infer recommendations from different information sources were manipulated accordingly in order to examine how such information was used by subjects in the decision-making process. (Note 7).

It is worth pointing out that a great advantage of our survey is that we fully controlled the information in each scenario. As noted previously, a big challenge for the empirical research on herd behavior is that there are no data on the information to the consumers. Hence, it is not easy to find out whether the consumers decide to disregard their own information and imitate. However, it now becomes possible to overcome such problem by using a survey. Information that subjects had was observed in our survey when they made decisions. By observing the way in which they used and reacted to the information, we were able to directly detect the occurrence of herding. This approach has improved our understanding of herd behavior in the insurance market and created a bridge between the empirical and theoretical literatures.

\subsection{Measures}

The dependent variable used in the model was the influence of the recommendation sources on insurance buyers' choices. The influence was measured by a dichotomous variable choice. Each choice was categorized as either a 
decision to buy from insurer A or from insurer B. (Note 8) Two dependent variables, exp_rating and cons_rating, were used to indicate ratings available to subjects from two different recommendation sources. (Note 9) In addition, each insurer's sales revenue and a list of individual demographic information collected from subjects were also included for necessary analysis. (Note 10).

\section{Results}

The results of logit models that use choice as the dependent variable are presented in the following tables.

Table 1 captures the significant impact of recommendations from two different information sources on insurance buyers' decision-making processes. In column 1 we present the model in which only the variable indicating ratings from an insurance expert is included. The variable exp_rating is significant at the $1 \%$ level in the model. Examining the results from this model, we find support for H1, suggesting that ratings from an insurance expert exert a positive influence and are followed in a great portion by insurance buyers. In other words, the insurer that is highly rated by the insurance expert is more likely to be chosen by subjects. In column 2 we include only ratings from other consumers in the survey. As illustrated, the variable cons_rating is also highly significant at the $1 \%$ level. This supports $\mathrm{H} 2$ set forth above concerning the positive impact of recommendations from other consumers on the insurance buyers' decision-making processes. We find that our subjects are more likely to purchase policy from the insurer that has relatively higher ratings from other consumers.

Table 1. Models for testing $\mathrm{H} 1$ and $\mathrm{H} 2$

\begin{tabular}{lcc}
\hline & $(1)$ & $(2)$ \\
\cline { 2 - 3 } Variables & Model1 Logit Coeff & Model2 Logit Coeff \\
\hline \multirow{2}{*}{ exp_rating } & $1.562^{* * *}$ & \\
& $(0.155)$ & $2.518^{* * *}$ \\
cons_rating & & $(0.173)$ \\
Constant & $-0.865^{* * *}$ & $-1.364^{* * *}$ \\
& $(0.111)$ & $(0.126)$ \\
Observations & & 776 \\
\hline
\end{tabular}

Note. Standard errors in parentheses.

$* * * \mathrm{p}<0.01, * * \mathrm{p}<0.05, * \mathrm{p}<0.1$.

Odds ratios for both models are reported in Table 2. It is straightforward to see that the chance for a consumer to buy insurance policy from an insurer that is highly rated by an insurance expert is almost 5 times of buying from a low-rated insurer. Such positive influence on consumers' decisions is even stronger if we switch the information source from insurance expert to other consumers. As shown in column 2 of this table, a potential buyer is nearly 12 times more likely to buy the same policy from a consumer highly-rated insurer.

Table 2. Models for testing $\mathrm{H} 1$ and $\mathrm{H} 2$ (odds ratio)

\begin{tabular}{lcc}
\hline & $(1)$ & $(2)$ \\
\cline { 2 - 3 } Variables & Model1 Odds Ratio & Model2 Odds Ratio \\
\hline \multirow{2}{*}{ exp_rating } & $4.766^{* * *}$ & \\
& $(0.738)$ & $12.41^{* * *}$ \\
cons_rating & & $(2.150)$ \\
Constant & $0.421^{* * * *}$ & $0.256^{* * *}$ \\
& $(0.0468)$ & $(0.0322)$ \\
Observations & & 776 \\
\hline
\end{tabular}


In order to test $\mathrm{H} 3$ to examine the relative strength of recommendations from insurance experts versus recommendations from other consumers in influencing insurance buyers' decision-making processes, we analyze three different models and report results in Table 3 and Table 4, respectively.

First, we examine model with full set of samples. We find significantly positive effects on both information sources. That is, our subjects are more likely to buy policy from the insurer that has been highly rated by either insurance experts or other consumers in the market. Findings from column 1 in Table 3 are consistent with findings that support first two hypotheses. Interestingly, we notice that the magnitude of influence from two information sources is different. As predicted by H3, column 1 of Table 4 shows that when given ratings from both experts and other consumers, it is more likely for subjects to follow recommendations from other consumers rather than from insurance experts. The odds ratio in the model for variable cons_rating is about 2 times of the odds ratio for variable exp_rating.

Table 3. Models for testing H3

\begin{tabular}{lccc}
\hline & $(1)$ & $(2)$ & $(3)$ \\
\cline { 2 - 4 } Variables & Model3 Logit Coeff & Model4 Logit Coeff & Model5 Logit Coeff \\
\hline exp_rating & $2.916^{* * *}$ & $-0.755^{* * *}$ & $(0.207)$ \\
& $(0.291)$ & & $0.755^{* * *}$ \\
cons_rating & $3.670^{* * *}$ & & $(0.207)$ \\
& $(0.292)$ & 0.228 & $-0.527^{* * *}$ \\
Constant & $-3.424^{* * *}$ & $(0.145)$ & $(0.149)$ \\
& $(0.293)$ & 388 & 388 \\
\hline
\end{tabular}

Note. Standard errors in parentheses.

$* * * \mathrm{p}<0.01, * * \mathrm{p}<0.05, * \mathrm{p}<0.1$.

Second, to demonstrate robustness of our findings, we test alternative models (Column 2 and Column 3 in Table 3 ) by only using samples in which two information sources recommend conflict ratings. That is, the insurer highly rated by one information source is however rated much lower by the other information source in the scenario. In column 2, the significantly negative logit coefficient indicates that buyers become less likely to follow recommendations from insurance experts when facing such conflict ratings. On the other hand, significantly positive logit coefficient in column 3 suggests positive influence of ratings from other consumers on buyers' choice even when conflict occurs. This interesting finding indicates that insurance buyers are more willing to use aggregated evaluations from other consumers rather than from field experts when they do observe conflicts. One possible explanation, as noted previously, is that consumers may believe that other consumers in the market have equal desire to share the best information which makes their opinions more informative and diagnostic compared to opinions from experts.

Table 4. Models for testing H3 (odds ratio)

\begin{tabular}{lccc}
\hline & $(1)$ & $(2)$ & $(3)$ \\
\cline { 2 - 4 } Variables & Model3 Odds Ratio & Model4 Odds Ratio & Model5 Odds Ratio \\
\hline exp_rating & $18.47^{* * *}$ & $0.470^{* * *}$ & $(0.0974)$ \\
cons_rating & $(5.383)$ & & $2.128^{* * *}$ \\
& $39.26^{* * *}$ & & $(0.441)$ \\
Constant & $(11.45)$ & 1.256 & $0.590^{* * *}$ \\
& $0.0326^{* * *}$ & $(0.181)$ & $(0.0877)$ \\
Observations & $(0.00955)$ & 388 & 388 \\
\hline
\end{tabular}

Note. seEform in parentheses.

$* * * \mathrm{p}<0.01, * * \mathrm{p}<0.05, * \mathrm{p}<0.1$.

In addition, we also test if releasing insurer's sales revenue will affect buyers' choices. Literature in the field of consumer research implies that some product information could have impact on consumers and further induce herd behavior in the market. For example, Chen (2008) investigates sales volume as one of cues leading to the 
online herd behavior among book readers. By providing each insurer's sale revenue to our subjects, we are able to investigate if such effect also exists in the insurance market. The results are presented in column 1 of Table 5 . Logit coefficient for the variable sale_rev shows that there is no effect of insurer's sales revenue on buyers' purchase decisions. This finding suggests that insurer's sales revenue may not be recognized as valuable information by consumers. One possible reason is that larger insurance firms with many different lines of business are believed to have higher sales revenues. (Note 11) The sales revenue alone fails to provide further positive correlations to the product quality or services most consumers are searching for. Besides, it is common and nature for consumers to link high sales revenue to high insurance costs to the insureds. Thus, it is not surprising that insurer's sales revenue has no impact on the consumers' choices.

Furthermore, information about the subjects' age, gender, major, and their insurance purchase experience collected in the survey was also used in the model as independent varibles for analysis. As illustrated in column 2 of Table 5, results of the model show that the subject's level of education, gender, major, and having previous experience with auto policy are not significant determinants of their purchase decisions when herd behavior occurs. Finally, as a robustness check, we also only use subjects who have auto policy purchase experience to test the influence of information sources on buyers' decision-making processes. It is interesting to see if information sources may have same level of impact on experienced buyers. Column 3 illustrates that those recommendations followed by inexperience buyers are also followed in the same way by experienced buyers.

Table 5. Models with sales revenue and personal demographic information

\begin{tabular}{lccc}
\hline & $(1)$ & $(2)$ & $(3)$ \\
\cline { 2 - 4 } Variables & Model6 Logit Coeff & Model7 Logit Coeff & Model8 Logit Coeff \\
\hline sales_rev & -0.112 & -0.113 & -0.118 \\
& $(0.194)$ & $(0.194)$ & $(0.217)$ \\
exp_rating & $2.917 * * *$ & $2.924^{* * *}$ & $2.962^{* * *}$ \\
& $(0.292)$ & $(0.292)$ & $(0.317)$ \\
cons_rating & $3.672^{* * *}$ & $3.682^{* * *}$ & $3.421^{* * *}$ \\
& $(0.292)$ & $(0.292)$ & $(0.318)$ \\
age & & -0.00483 & 0.0954 \\
& & $(0.0588)$ & $(0.134)$ \\
gender & & -0.171 & -0.240 \\
business & & $(0.203)$ & $(0.228)$ \\
auto_ins & & -0.164 & -0.0283 \\
& & $(0.238)$ & $(0.262)$ \\
Constant & & 0.178 & $(0.265)$ \\
Observations & $-3.369^{* * *}$ & $-3.221^{* *}$ & $(1.437)$ \\
\hline
\end{tabular}

Note. Standard errors in parentheses.

$* * * \mathrm{p}<0.01, * * \mathrm{p}<0.05, * \mathrm{p}<0.1$.

\section{Conclusions}

The purpose of this paper is to examine the herd behavior in the insurance market to improve our understanding of how different information sources impact buyers' decision-making processes. Our results strongly support contentions that insurance buyers are influenced in their choices by recommendations from different information sources and they do use these herd cues to infer product quality when making their purchase decisions. However, these two information sources, recommendations from human experts and from other consumers, are not equally influential. Recommendations from other consumers were found to be relatively more influential even if they were perceived as possessing less expertise than experts in the insurance field.

Our paper's main implication is related to the influence of information sources on insurance buyers' herd behavior. With the emergence of new technology available in the market, consumers now have more access to various information sources that can provide insurance product information and recommendations. One conventional recommendation source widely used by the insurance firm to sell products in the market is through its agency system because these professionals are believed by consumers to represent level of expertise. 
However, our results show that recommendations of other consumers are considered a more trustworthy source of recommendations than are experts. Thus, using information sources that create interesting consumption experience from existing consumers, insurers may find a more efficient way to pair loyal consumers with new potential consumers.

This paper also has implications for insurance regulatory agency. Our results show that recommendations from information sources (insurance experts and other consumers) influence consumers' insurance purchase choices. Further, this influence is moderated by the type of source. Thus, results suggest that it is important and essential for the regulatory agency to monitor how insurers use these herd cues to stimulate their sales in the insurance market and guide consumers make better decisions.

Finally, our paper also points to future research avenues. First, like any experimental study, the presence of self-selection bias may make it relatively hard to have our subjects to represent the population of all insurance buyers in the market. Future research may examine the herding in a real market environmental setting instead. Second, literature on consumer research has shown that product characteristics such as type are believed to impact consumer purchase behavior. However, our survey only focuses on one general insurance product, namely, auto insurance policy, to elicit herding among potential buyers in the market. Thus, further studies using a variety of insurance products would be much helpful to generalize the findings of our study.

\section{References}

Anderson, L. R., \& Holt, C. A. (1997). Information Cascades in the Laboratory. American Economic Review, 87(5), 847-862.

Andreasen, A. R. (1968). Attitudes and Customer Behavior: A Decision Model. In H. Kassarjian, \& T. S. Robertson (Eds.), Perspectives in Consumer Behavior (pp. 498-510). Scott, Foresman and Company, Glenview, IL.

Ansari, A., Essegaier, S., \& Kohli, R. (2000). Internet Recommendation Systems. Journal of Marketing Research, 37(3), 363-375. http://dx.doi.org/10.1509/jmkr.37.3.363.18779

Asch, S. E. (1956). Studies of Independence and Conformity: A Majority of One against a Unanimous Majority. Psychological Monographs, 70-79. http://dx.doi.org/10.1037/h0093718

Avery, C., \& Zemsky, P. (1998). Multidi-mensional Uncertainty and Herd Behavior in Financial Markets. American Economic Review, 88(4), 724-748.

Banerjee, A. (1992). A Simple Model of Herd Behaviour. Quarterly Journal of Economics, 107(3), 797-817. http://dx.doi.org/10.2307/2118364

Bikhchandani, S., Hirshleifer, D., \& Welch, I. (1992). A Theory of Fads, Fashion, Custom, and Cultural Change in Informational Cascades. Journal of Political Economy, 100(5), 992-1026. http://dx.doi.org/10.1086/261849

Bonabeau, E. (2004). The Perils of the Imitation Age. Harvard Business Review, Jun(1), 45-54.

Chamley, C. (2004). Rational Herds: Economic Models of Social Learning. Cambridge University Press.

Chen, Y. F. (2008). Herd Behavior in Purchasing Books Online. Computers in Human Behavior, 24(5), 1977-1992. http://dx.doi.org/10.1016/j.chb.2007.08.004

Cipriani, M., \& Guarino, A. (2005). Herd Behavior in a Laboratory Financial Market. American Economic Review, 95(5), 1427-1443. http://dx.doi.org/10.1257/000282805775014443

Cipriani, M., \& Guarino, A. (2009). Herd Behavior in Financial Markets: An Experiment with Financial Market Professionals. Journal of the European Economic Association, 7(1), 206-233. http://dx.doi.org/10.1162/JEEA.2009.7.1.206

Cummins, J. D., McGill, D., Winklevoss, H., \& Zelten, H. (1974). Consumer Attitudes toward Auto and Homeowners Insurance. Department of Insurance, Wharton School, University of Pennsylvania, Philadelphia.

Dahlby, B., \& West, D. S. (1986). Price Dispersion in an Automobile Insurance Market. Journal of Political Economy, 94, 418-438. http://dx.doi.org/10.1086/261380

Gale, D. (1996). What Have We Learned from Social Learning? European Economic Review, 40, 617-628. http://dx.doi.org/10.1016/0014-2921(95)00074-7

Gilly, M. C., Graham, J. L., Wolfinbarger, M. F., \& Yale, L. J. (1998). A Dyadic Study of Personal Information 
Search. Journal of the Academy of Marketing Science, 26(2), 83-100. http://dx.doi.org/10.1177/0092070398262001

Hirshleifer, D., \& Teoh, S. H. (2003). Herd Behaviour and Cascading in Capital Markets: A Review and Synthesis. European Financial Management, 9(1), 25-66. http://dx.doi.org/10.1111/1468-036X.00207

Johnson, E., Hershey, J., Meszaros, J., \& Kunreuther, H. (1993). Framing, Probability Distortions, and Insurance Decisions. Journal of Risk and Uncertainty, 7, 35-51. http://dx.doi.org/10.1007/BF01065313

Kelley, H. H. (1967). Attribution Theory in Social Psychology. In D. Levine (Ed.), Nebraska Symposium on Motivation (pp. 192-241). Lincoln, NE: University of Nebraska Press.

Kelman, H. C. (1961). Processes of Opinion Change. Public Opinion Quarterly, 25(1), 57-78. http://dx.doi.org/10.1086/266996

Kunreuther, H., \& Pauly, M. (2004). Neglecting Disaster: Why Don't People Insure against Large Losses? Journal of Risk and Uncertainty, 28, 5-21. http://dx.doi.org/10.1023/B:RISK.0000009433.25126.87

Kunreuther, H., \& Pauly, M. (2005). Insurance Decision-making and Market Behavior. Foundations and Trends in Microeconomics, 1, 63-127. http://dx.doi.org/10.1561/0700000002

Lascu, D. N., \& Zinkhan, G. (1999). Consumer Conformity: Review and Applications for Marketing Theory and Practice. Journal of Marketing Theory and Practice, 7(3), 1-12.

Laury, S. K., \& McInnes, M. M. (2003). The Impact of Insurance Prices on Decision Making Biases: An Experimental Analysis. Journal of Risk and Insurance, 70(2), 219-233. http://dx.doi.org/10.1111/15396975.00057

Liu, F. (2015). Accident Forgiveness in the Automobile Insurance Contract. International Journal of Economics and Finance, 7(3), 68-85. http://dx.doi.org/10.5539/ijef.v7n3p68

McGuire, W. J. (1969). The Nature of Attitudes and Attitude Change. In G. Lindzey, \& E. Aronson (Eds.), The Handbook of Social Psychology (pp. 137-314). Reading, MA, Addison-Wesley Publishing Company.

Park, W. C., \& Lessig, P. V. (1977). Students and Housewives: Differences in Susceptibility to Reference Group Influence. Journal of Consumer Research, 4(2), 102-110. http://dx.doi.org/10.1086/208685

Schlesinger, H., \& Schulenburg, J. M. (1993). Consumer Information and Decisions to Switch Insurers. Journal of Risk and Insurance, 60(4), 591-615. http://dx.doi.org/10.2307/253381

Senecal, S., \& Nantel, J. (2004). The Influence of Online Product Recommendations on Consumers' Online Choices. Journal of Retailing, 80(2), 159-169. http://dx.doi.org/10.1016/j.jretai.2004.04.001

Shiller, R. J. (2001). Human Behavior and the Efficiency of the Financial System. Cowles Foundation Paper NO.1025, Yale University.

Surowiecki, J. (2004). The Wisdom of Crowds. New York, NY, Doubleday.

Wangenheim, F. V., \& Bayon, T. (2004). The Effect of Word of Mouth on Services Switching: Measurement and Moderating Variables. European Journal of Marketing, 38(9/10), 1173-1185. http://dx.doi.org/10.1108/03090560410548924

Welch, I. (1992). Sequential Sales, Learning, and Cascades. Journal of Finance, 47(2), 695-732. http://dx.doi.org/10.1111/j.1540-6261.1992.tb04406.x

\section{Notes}

Note 1. Consumers may have opportunities to read relevant policy contents before they actually purchase the policies. However, "quality" of the insurance product has much wider definition. For example, the quality of services provided by the insurers is also commonly considered as part of the quality of the insurance products.

Note 2. For example: Chamley (2004), Cipriani and Guarino (2005, 2007), Gale (1996), Hirshleifer and Teoh (2003).

Note 3. For example: Gilly et al. (1998).

Note 4. A certified financial planner (CFP) is licensed to sell or give advice on insurance products.

Note 5. See Surowiecki (2004).

Note 6. In this survey, subjects were informed that ratings from other consumers were adopted from a consumer 
survey which purely collected consumers' opinion of insurers.

Note 7. For example, in some scenarios both the insurance expert and other consumers recommended the same insurer while in other scenarios they recommended different insurers.

Note 8 . The variable choice takes value 1 if the subject chooses to buy auto policy from insurer B.

Note 9. The variable exp_rating takes value 1 if insurer B is rated higher than insurer A by an insurance expert. Otherwise, it takes value 0 . This rule is also applied to the variable cons_rating.

Note 10. We included subject's age, gender, major and whether s/he has auto policy purchase experience. The dummy variable for experience takes value 1 if the subject has such purchase experiences and 1 otherwise.

Note 11. Most insurers listed as top 10 by SNL Financial in the U.S. are multi-line business insurance firms. Example, Allstate, the third largest property casualty insurer, also provides life insurance and retirement products.

\section{Copyrights}

Copyright for this article is retained by the author(s), with first publication rights granted to the journal.

This is an open-access article distributed under the terms and conditions of the Creative Commons Attribution license (http://creativecommons.org/licenses/by/3.0/). 